\title{
WASCON 2015: Resource Efficiency in Construction
}

\author{
Carlo Vandecasteele ${ }^{1} \cdot$ Ana Andres ${ }^{2} \cdot$ Alberto $\mathrm{Coz}^{2}$
}

Published online: 8 July 2017

(c) Springer Science+Business Media B.V. 2017

The 9th International Conference on the Environmental and Technical Implications of Construction with Alternative Materials "WASCON 2015: Resource Efficiency in Construction" took place from 10 to 12 June 2015, in the beautiful 'Palacio de la Magdalena' in Santander, Cantabria (Spain). It was organised by the GER Research Group, Green Engineering and Resources of the University of Cantabria together with ISCOWA. WASCON is the reference international conference on the use of alternative materials in construction. It has been held every 3 years since 1991 and provides a forum for exchange of ideas and current research on the use of waste, industrial by-products and other recycled materials in construction. One hundred eighty people from 24 countries and from 5 continents participated in the 3-day conference. These participants represented private companies, research and technological centers, universities, professional associations and administrations. The program consisted of 4 plenary lectures, 62 oral presentations, 34 flash presentations and 25 posters. The day before the start of the conference a LeachXS training course was organized, in which 20 students participated.

Already from the start of the series of WASCON conferences, we were convinced that the construction sector was the field of choice for the use of waste, industrial by-products and other recycled materials as 'secondary raw materials' [1], as this sector is probably the largest consumer

Ana Andres

ana.andres@unican.es

1 Department of Chemical Engineering, University of Leuven, Heverlee, Belgium

2 Department of Chemistry and Process and Resource Engineering, University of Cantabria, Santander, Spain of resources and the largest waste generator, and because it has large environmental impact. In a recent report [2], it was stated that construction and use of buildings accounts in the EU for about half of the extracted materials and of the energy consumption and for about one-third of the water consumption. The sector also accounts for 25-30\% of the waste generated in the EU. Moreover, environmental pressures arise at all stages of the construction life cycle, including the manufacturing of construction products, physical construction, use of buildings, renovation and the management of waste. On the other hand, construction products affect the performance of buildings with respect to safety, health, environmental performance and energy efficiency. In a recent report [3] it was mentioned that sustainable use of resources relates to recyclability, durability and the use of environmentally compatible materials.

As full title of the conference "WASCON 2015: Resource Efficiency in Construction" was selected. A lot of attention was given to the following topics mentioned in the previous paragraph and related to resource efficiency: manufacturing of construction products using alternative raw materials, recycling to manage construction and demolition waste, construction products and environmental performance, recyclability, durability and environmental compatibility of materials. The material presented at the various WASCON conferences was for the major part in line with what is now called 'the circular economy'. We are sure WASCON thus contributed to this area even before the term was in current use [4].

Recently several initiatives were taken and reports appeared showing that 'resource efficiency in construction' is also considered a high priority issue by the authorities and in industry. 
- The "EU Strategy for the sustainable competitiveness of the construction sector and its enterprises" focuses on five objectives, including resource efficiency [5].

- The Construction Products Regulation CPR has been implemented in 2011. As this is a relatively short time ago, not all its objectives have been achieved yet [5].

- Regarding the economic impact of the CPR, a current study has shown that further indirect benefits are generated, as relevant harmonized European product standards are adopted [6].

- In October 2016 the "Supporting Study for Fitness Check on the Construction Sector in relation to EU Environment, Health and Safety Legislation" was published, which focuses on the impact of relevant legislation in the construction sector [2].

- The implementation of the Circular Economy Action Plan in the construction sector encompasses a wide range of initiatives, and reuse and recycling activities [7].

- An industry-wide voluntary protocol on the management of Construction and Demolition Waste was published in 2016 [8].

- It was shown that the introduction of circular economy strategies in a high impact sector like construction contributes to reduction of GHG emissions and therefore to significant climate change mitigation [9].

We wanted, as in the past (Waste and Biomass Valorization, December 2013, Volume 4, Issue 4) to make a selection of the papers of WASCON 2015 available to the readers of Waste and Biomass Valorization. This selection includes technical papers about using waste like mining waste, glass, fly ash, MSW residues, sludge, slag, etc., as raw material to produce bricks, cement, aggregates for use in concrete, etc. Other papers investigate the influence of recycled aggregate quality on concrete properties, evaluate the European recovery target for construction and demolition waste, compare by LCA the production of stone wool using traditional or alternative materials, and discuss MSWI bottom ash treatment in view of recycling in construction.

We hope that reading these papers will inspire you and will also encourage you to attend the Tenth International Conference on the Environmental and Technical Implications of Construction with Alternative Materials "WASCON 2018", which will be held in Tampere, Finland from 6 to 8 June 2018, organised by the Finnish Association of Civil Engineers, RIL, and ISCOWA. For more information: http://www.wascon2018.com.

\section{References}

1. Vandecasteele, C., Heynen, J., Goumans, H.: Materials recycling in construction: a review of the last 2 decades illustrated by the WASCON conferences. Waste Biomass Valor. 4(4), 695-701 (2013)

2. Fleet, D.: Supporting study for fitness check on the construction sector-the second phase on EU environment, health and safety legislation executive summary. Ref. Ares 6264099-04/11/2016 (2016)

3. The European Construction Sector: A global partner. Ref. Ares 1253962 -11/03/2016 (2016)

4. Regulatory barriers for the circular economy lessons from ten case studies. Final Report Technopolis Group, (2016)

5. Report on the implementation of Regulation (EU) No 3052011 of the European Parliament and of the Council of 9 March 2011 laying down harmonized conditions for the marketing of construction products and repealing Council Directive 89/106/EEC (2011)

6. Economic Impacts of Construction Products Regulation. Final report written by VVA Europe, the Danish Technological Institute (DTI) and the Netherlands Organization for Applied Scientific Research (TNO) (2016)

7. Report on the implementation of the Circular Economy Action Plan from the European Parliament, the Council, the European Economic and Social Committee and Committee of the Regions, COM 33 final (2017)

8. EU Construction and Demolition Waste Management Protocol. Ref. Ares 6914779-12/12/2016 (2016)

9. Circular Economy Potential for Climate Change Mitigation. Final report Deloitte sustainability (2016) 